\title{
Advances in Mechanical Circulatory Support in the Treatment of Heart Failure
}

\author{
Claudio Leo Gelape ${ }^{1}$ and Si M. Pham² \\ Universidade Federal de Minas Gerais - Hospital das Clinicas', Belo Horizonte, MG, Brasil; University of Miami (Miller School of Medicine) - \\ Jackson Memorial Hospital'2, Miami, USA
}

\section{Summary}

Heart failure (HF) is a chronic and debilitating illness. In the United States, 250,000-500,000 patients are at the endstage of HF refractory to medical treatment. The prognosis of these patients is poor, with median survival of 3 to 4 months and $6 \%$ in one year for those inotrope-dependent patients. Because of the high mortality observed in the presence of $\mathrm{HF}$, the use of mechanical circulatory support is in many cases the only chance of survival while waiting for a donor. In recent years, the implantation of Ventricular Assist Devices (VAD) as definitive therapy (DT) has emerged as a promising replacement therapy for heart transplantation. There is a gap between the demand of patients for DT and the actual number of procedures performed, which reflects ignorance about the new technology as well as reluctance to refer patients earlier. Studies have shown superior survival between the VAD and clinical treatment, and significant improvement in the quality of life of patients maintained on VAD. The one-year survival of $75 \%$ with continuous flow VAD provided a target to be hit by ventricular assist therapy. In Brazil, the lack of financial support by the health agencies has not yet allowed patients to access mechanical support in the treatment of heart failure.

Heart failure (HF) is an epidemic illness. It is estimated that 5.7 million people have HF in the United States and 300,000 deaths/year occur for some complication of the disease. Heart failure affects 1 in every 100 adults older than 65 years and is responsible for 1.1 million hospitalizations in the United States, leading to expenditures of 37.2 billion dollars annually ${ }^{1,2}$. Despite all therapies available, the prognosis of HF remains dismal $^{3-5}$. Mortality at 1 and 5 years with clinical treatment is $30 \%$ and $60 \%$, respectively ${ }^{6}$. The number of patients refractory to this therapy varies from $0.5 \%$ to $5 \%$, with reports of significant increase in these numbers in the last years ${ }^{7}$. In addition, the mortality of first hospitalization can reach $33 \%{ }^{8}$.

\section{Keywords}

Heart failure/mortality; advanced cardiac life support/ trends; heart failure/therapy; heart-assist devices.

\section{Mailing Address: Claudio Leo Gelape •}

Rua Bernardo Guimarães, 640 / 504 - 30140-660 - Funcionários, Belo Horizonte, MG, Brazil

E-mail: clgelape@uol.com.br, clgelape@uai.com.br

Manuscript received September 20, 2011; revised manuscript received November 07, 2011; accepted November 10, 2011.
Frequent re-hospitalizations ( $20 \%$ of patients return to hospital at 1 month and $50 \%$ in 6 months) contribute to the reduction in quality of life ${ }^{8,9}$.

Oral agents (angiotensin-converting enzyme inhibitors, angiotensin receptor blockers, aldosterone inhibitors and beta blockers) are the mainstay of clinical treatment of chronic heart failure, but an improvement of only $3 \%$ to $9 \%$ survival is reported ${ }^{4}$. The functional capacity experienced by patients with drug treatment is very low. Intravenous agents such as dobutamine and milrinone, often used to stabilize hemodynamics, increase mortality by $50 \%$ in 6 months, and $80 \%$ at 1 year ${ }^{5,10}$. This scenario clearly suggests that medical therapy is suboptimal and that the pharmacological neurohormonal blockade appears to be safe and effective ${ }^{11}$.

Mechanical Circulatory Support (MCS) of short duration can be used in acute HF especially in acute myocardial infarction and cardiogenic shock ${ }^{12}$. In the treatment of chronic HF the only definitive therapy is heart tx (TX) that can offer functional capacity, quality of life and better long-term survival expectancy $^{13}$. However, considering the gap between potential candidates and donations, the TX is often an improper option. In this context, the MCS with Ventricular Assist Devices (VAD) has become an attractive option. These devices offer assistance to ill hearts, which is usually maintained to serve as a pump or support or as a conduit to fill the device ${ }^{14}$. The VAD therapy can act as a bridge to the future transplant (TB), a possible bridge to recovery of the heart or as definitive therapy (DT).

Technological progress has contributed to the development of continuous pulsatile blood flow pumps ${ }^{15}$. The early implantation of devices and the lower rate of complications improved survival after use of VAD, which can get closer to that of the TX in some reports ${ }^{16}$. Therefore, VAD are currently considered a safe option when used in patients of NYHA functional class III and IV ${ }^{17}$. However, the more frequent use of VAD has been limited by the size of devices and various adverse events related to them, such as infection, bleeding, embolization and mechanical problems.

\section{Advances of VAD}

In 1963, DeBakey implanted the first VAD in a patient after surgery for aortic valve replacement ${ }^{18}$. Since 1964, the National Heart, Lung, and Blood Institute (NHBLI) has sponsored the development of devices for short and long term circulatory support, including the total artificial heart ${ }^{19}$. Since then, the VAD has been used in the USA for different therapeutic approaches. The HeartMate XVE (Thoratec, 
Pleasanton, CA) was approved as PT in $1994^{20}$ after a multicenter clinical evaluation, when a $65 \%$ survival rate with VAD as TB vs. $50 \%$ with medical treatment was revealed ${ }^{21}$.

The study REMATCH (Randomized Evaluation of Mechanical Assistance in Treatment of Chronic Heart Failure) evaluated the benefit of the VAD as a DT in patients not candidates for TX. ${ }^{4}$ From 1998 to 2001, out of 129 patients randomized, 68 received pulsatile VAD and 61 were kept under clinical treatment. There was a reduction in mortality in $48 \%$ of patients receiving the device. The one-year survival was $52 \%$ for VAD group vs. $25 \%$ of the medical group, and two-year survival as $23 \%$ for the VAD group vs. $8 \%$ for the clinical group, $p=0.009$. The difference in survival (408 days for the VAD group and 150 for the clinical group) marked the FDA approval of this device as DT ${ }^{22}$. From 1,000 patients with HF, 270 deaths/year can be prevented, while with clinical treatment only 70 are prevented ${ }^{23,24}$. The study INTRePID (Investigation of Nontransplant-Eligible Patients Who Are Inotrope Dependents), a prospective randomized trial from 2000 to 2003, compared survival in 55 patients with HF on use of inotropic agents to patients implanted with pulsatile VAD (NOVACOR) as a DT. Patients with VAD showed better survival at six months ( $46 \%$ vs. $22 \%, p=0.03$ ) and in one year $(27 \% \text { vs. } 11 \%, p=0.02)^{10}$. These results were added to the REMATCH study demonstrating the benefit of the VAD as a DT in patients with HF at an advanced functional class. The authors concluded that it would not be ethical to perform randomization between VAD and medical therapy with inotropic agents, since the benefit with the devices was evident. Stevenson et al. analyzed 91 REMATCH patients on use of inotropic agents and demonstrated that the benefit of VAD was really significant. These authors reported $60 \%$ survival of the VAD group vs. $39 \%$ of the clinical group in six months, and $49 \%$ of the VAD group vs. $24 \%$ of the clinical group in one year, $p=0.0014^{25}$.

The first generation of VAD was developed with pulsatile flow through pneumatic propulsion. These machines had an inconvenient noise, local discomfort due to their large size and frequent mechanical problems ${ }^{16}$. The second generation were the continuous flow VADs that drive the blood through a small impeller (high speed system) that provides a flow of 8 to $10 \mathrm{~L} / \mathrm{min}^{26}$. With this design the machines do not require valves, so they are lighter and smaller, and silent ${ }^{27}$. The third-generation devices use a magnetic levitation system in which the impeller has no mechanical contact to move. Theoretically, this system may be more durable with less mechanical effect on blood components. ${ }^{18}$ Physiologically, after implantation of the VAD, there are reduced filling pressures, increased cardiac output and increased peripheral perfusion. Consequently, there is an improvement of right ventricular and renal function ${ }^{28}$.

There are several devices available. The most used ones are DeBakey VAD (MicroMed, Houston, TX), HeartMate II (Thoratec, Pleasanton, CA), DuraHeart (Terumo, Ann Arbor, MI), Incor (Berlin Heart) and HeartWare (HeartWare, Framingham, MA). More than 4,000 devices equipped with first-generation pulsatile pumps were implanted ${ }^{29}$. The miniaturization of the systems provided intrapericardial implant and biventricular assist ${ }^{30}$.
In 2007, Miller et al ${ }^{31}$ conducted an observational study of centrifugal pumps used as TB. One hundred and thirty-three patients at 26 U.S. centers participated in the study between 2005 and 2006. All patients were on inotropic use at the time of VAD implantation and $41 \%$ of patients used intraaortic balloon. Patients were followed until the TX, recovery or survival up to three months, which was $75 \%$. The results demonstrated the safety of centrifugal pumps and lower infection rate compared to published reports on pulsatile pumps. Later, a study by Pagani et al. in $2009^{32}$ presented 281 patients with VAD kept in up to 18 months. Survival was $72 \%$. Deaths occurred in the first three months of the implant by stroke, infection and multiple organ failure.

In a study conducted in 38 U.S. centers, Slaughter et $\mathrm{al}^{17}$ in 2009, compared pulsed continuous VAD as DT. The devices used were HeartMate XVE (pulsatile) and HeartMate II (continuous). One hundred and thirty-four patients received continuous VAD and 59 received the pulsatile VAD. Survival at one and two years for the continuous group was $68 \%$ and $58 \%$ respectively; while for the pulsatile group, it was 55\% and $24 \%, p=0.008{ }^{17}$. Using the continuous VAD, there was a reduction of re-hospitalizations of $38 \%$. The authors concluded that continuous VADs provided improved survival and quality of life compared to pulsatile devices that had higher rates of infection and mechanical failure.

Results of studies after FDA approval of VADs demonstrate continued increased survival and lower complication rates. One-year survival improved significantly from $68 \%{ }^{31}$ reaching levels of $85 \%$ in the last reports ${ }^{33}$. Experience gains with clinical and surgical management, appropriate selection of patients and continuous training of the technical staff involved with pre and post-operative care have contributed to the improvement of results ${ }^{34,35}$.

In order to organize data generated by U.S. institutions that implant VADs, the INTERMACS was created in 2006 to serve as a database sponsored by the $\mathrm{NHLBI}^{36}$. Data generated by INTERMACS provided technical improvements and standardization of clinical and surgical management ${ }^{16}$. Data collection occurs on a prospective and binding basis, which allows detailed analysis of related events, reliability of the devices approved by the FDA, morbidity and mortality of patients. The goal of the registration is to investigate, facilitate and improve the use of VADs as a MCS in the long term in patients with advanced $\mathrm{HF}^{37}$. With the same object, Europe created EUROMAC (European registry for patients in mechanical circulatory support) and tabulated data to be published in the future. Regarding the first registration, INTERMACS had 89 hospitals registered by December 2007, with 511 patients included ${ }^{37}$. Forty-four percent of patients were in cardiogenic shock at the time of implantation of the pulsatile VAD, the only one approved by the FDA at that time. One-year survival was $67 \%$. In the second INTERMACS registration, more than 34,000 patients had gone through surgery $^{34}$. This report shows the change in pulsatile VAD implantation for continuous flow (52\% of the cases) ${ }^{34}$ approved in 2008 as TB. There were also indications of earlier devices implanted. Between 2006 and 2009, 1,420 patients from 88 institutions were registered. One-year survival was 74\% and in two years, 55\%. The third record was released in 2011 and 


\section{Clinical Update}

shows 2,868 patients with VAD from 79 institutions. In the first six months of $2010,98 \%$ of VADs were used for continuous flow with preponderance of isolated left ventricular support. Survival at one and two years was $79 \%$ and $66 \%$, respectively ${ }^{36}$. A change in the strategy of the implants is evident in the last five years, favoring the implantation of the VAD as DT ${ }^{36}$. In 2010, Lahpor et $\mathrm{al}^{38}$ showed the results with the implantation of the VAD Heartmate II in Europe. Sixty-four centers participated in the survey, which showed results similar to those of the U.S. centers (69\% survival to the TX, recovery or support in six months).

With reports of improved survival with continuous VAD, the medical community seems to be moving forward in the expansion of indications of MSC in patients with severe HF. It is essential to integrate these results into daily practice. Patients and doctors need to know that this technology is available, is effective and safe $^{14}$, and provides good functional capacity and hemodynamic recovery ${ }^{39}$.

\section{Long-term VAD interaction}

After implantation of intracorporeal VAD, patients experience the greatest part of their future treatment on an outpatient basis, often returning to work and family life ${ }^{16,40}$. These data are relevant, since in Brazil and worldwide there is a small number of organs available for the TX. Moreover, the rate of utilization of donated organs is small (20\% in Brazil vs. $50 \%$ in the U.S. $)^{41}$, which may favor the increase of VAD implantation.

The criteria for indication of VADs were based on data generated by INTERMACS7. It indicates the VAD as DT if the patient has presented NYHA class IV for at least 90 days and a life expectancy shorter than two years, is not a candidate for TX, has optimal medical treatment, ejection fraction smaller than $25 \%$ and clinical picture with limited functional capacity ${ }^{35}$. Thus, it is recommended that, in reliance on intravenous inotropic agents - associated with high mortality in the short term therapies such as VAD and TX should be considered.

VAD receives C-level class Ila indication for TB and C-level class IIb for DT from ESC (European Society of Cardiology) ${ }^{42}$ and B-level class Ila for DT from the ACC/AHA (American College of Cardiology/American Heart Association) ${ }^{43}$. The II Brazilian Guidelines on Chronic HF indicates VAD in the treatment of HF stage D in selected cases $^{44}$.

\section{Complications}

Many complications have been reported after surgery for implantation of VAD. The most frequent complications are multiple organ failure, neurological events, bleeding, sepsis and right ventricular failure (RVF). In the long term, neurological embolic or hemorrhagic events, HLA sensitization, renal failure, infection, mechanical dysfunction, gastrointestinal bleeding and psychological changes may dominate the clinical care setting ${ }^{45}$.

Bleeding is one of the most common and limiting complications. In the study by Miller et $\mathrm{al}^{31}$ bleeding was the most common adverse event. $53 \%$ of patients required at least two units of blood transfusion $^{31}$. There is a combination of factors that contribute to this fact, such as coagulation disorders, liver dysfunction and even major surgery ${ }^{6}$. In the second report of INTERMACS, this complication was the second most frequent adverse event after infection. Nevertheless, the primary cause of bleeding was only
$6.7 \%$ of deaths ${ }^{34}$, which reflects good clinical management of patients postoperatively.

During the MCS, the aortic valve can open and close less frequently or may remain closed. During circulatory support, there is a subphysiological condition within the LV cavity with potential development of significant aortic regurgitation in subsequent years. Regurgitant flow produces a vicious cycle that leads, as a consequence, to an increase of the volume ejected into the aorta by the VAD and progressive LV dilation, which favors the development of mitral regurgitation. For this reason, some institutions recommend aortic valve replacement or valve closure at the time of implant to prevent future complications ${ }^{26,46}$.

It is recommended to use prophylactic anticoagulants and antiplatelet therapy in the follow-up of patients with VAD in order to prevent thromboembolic events that occur between $30 \%$ and $50 \%$ postoperatively. These events are associated with serious sequelae and may limit the long-term success of VADs. High hyporesponsiveness to aspirin commonly observed in this group of patients is reported, which partially explains the frequency of complications ${ }^{47}$.

The use of VAD can also be associated with neurological complications (stroke, transient ischemic attack, cognitive dysfunction), which account for $34 \%$ of all deaths in patients after $\mathrm{VAD}^{48}$. Support time, device type, presence of infection and age are risk factors associated with neurological complications. The acquisition of Won Willebrand factor deficiency often occurs in patients with Heartmate II and appears to contribute to episodes of spontaneous bleeding in the postoperative period ${ }^{49}$. The MCS with continuous flow increases the diastolic pressure in the capillary and the arteriole from end organs mainly the brain, kidneys and gastrointestinal tract. This may explain the appearance of arteriovenous malformations causing bleeding in the digestive tract $^{22,48}$.

Serious infections and sepsis are among the most common complications after implantation of the VAD with an incidence of $18 \%$ to $59 \%{ }^{50,51}$. In the REMATCH study ${ }^{4}$, infection was the cause of death in $16.2 \%$ of patients. There is an increase in hospital costs, increased morbidity and mortality ${ }^{52}$ although recent reports show no such association ${ }^{53,54}$. Although there is lack of uniformity in the definitions of infection in patients with VAD, the current consensus is that this is a common complication in the setting of treatment with VAD and Staphylococcus and Pseudomonas, Enterococcus and Candida are the most usual ones ${ }^{55}$. Table 1 shows the incidence of infection and bleeding after implantation of VAD observed in the main works.

One of the most common infections relates to the power transfer cable for the VAD operation. These cables are brought out subcutaneously and are fixed to the skin. Infectious processes usually are established in the immediate or mediate postoperative period and require aggressive and quick treatment ${ }^{56}$. Procedures such as use of meticulous surgical technique, smaller prosthesis design and thinner transmission lines, the use of continuous flow VAD and totally implantable devices can decrease the incidence of infection ${ }^{57,58}$. However, despite these precautions, the infection can normally extend to the region where the device is implanted (pouch), requiring prosthesis explantation. Reliable transcutaneous energy transfer is under development, which could significantly reduce the incidence of infections ${ }^{59}$. 
Clinical Update

Table 1 - Incidence of infection and postoperative bleeding from implantation of VAD

\begin{tabular}{|c|c|c|c|c|c|c|}
\hline Author & Year & Patients & Device & Proposal & Incidence/prevalence - E/py* & Bleeding - E/py* \\
\hline \multirow{2}{*}{ Miller ${ }^{31}$} & \multirow{2}{*}{2007} & \multirow{2}{*}{133} & \multirow{2}{*}{$\mathrm{HMII} \dagger$} & \multirow{2}{*}{ TB $\ddagger$} & Sepsis $-0,62$ & \multirow{2}{*}{0,78} \\
\hline & & & & & Driveline $-0,37$ & \\
\hline \multirow{2}{*}{$\begin{array}{l}\text { REMATCH } \\
\text { Rose }^{4}\end{array}$} & \multirow{2}{*}{2001} & \multirow{2}{*}{67} & \multirow{2}{*}{ HM XVE } & \multirow{2}{*}{ DT§ } & Sepsis $-0,60$ & \multirow{2}{*}{0,56} \\
\hline & & & & & Driveline $-0,39$ & \\
\hline \multirow{2}{*}{$\begin{array}{l}\text { REMATCH } \\
\text { Rose }^{4}\end{array}$} & \multirow{2}{*}{2001} & \multirow{2}{*}{67} & \multirow{2}{*}{ HM XVE } & \multirow{2}{*}{ DT } & Sepsis - 0,60 & \multirow{2}{*}{0,56} \\
\hline & & & & & Driveline - 0,39 & \\
\hline \multirow{2}{*}{ Starling ${ }^{33}$} & \multirow{2}{*}{2011} & \multirow{2}{*}{169} & \multirow{2}{*}{ HM II } & \multirow{2}{*}{ TB } & Sepsis $-0,02$ & \multirow{2}{*}{1,44} \\
\hline & & & & & Driveline $-0,32$ & \\
\hline \multirow{2}{*}{ Strueber ${ }^{6}$} & \multirow{2}{*}{2011} & \multirow{2}{*}{50} & \multirow{2}{*}{ HeartWare } & \multirow{2}{*}{ TB } & Sepsis $-0,10$ & \multirow{2}{*}{0,23} \\
\hline & & & & & Driveline $-0,20$ & \\
\hline \multirow{4}{*}{ Slaughter ${ }^{17}$} & \multirow{4}{*}{2009} & \multirow{4}{*}{200} & \multirow[t]{2}{*}{ HM II } & & Sepsis $-0,39$ & \multirow{2}{*}{0,23} \\
\hline & & & & T & Inf/related - 0,48 & \\
\hline & & & \multirow[t]{2}{*}{ HM XVE } & DI & Sepsis $-1,11$ & \multirow{2}{*}{0,29} \\
\hline & & & & & Driveline $-0,90$ & \\
\hline
\end{tabular}

VAD - Ventricular Assist Devices; ${ }^{*} E / P y$ - Rate of event per patient per year; $†$ - Heartmate II; $\ddagger$ - TB - transplant bridge; $\S$ - DT - destination therapy; HM II - HeartMate II; M XVE- Heart Mate XVE.

The RV failure is not infrequent after the implantation of VAD. It is estimated that $20 \%$ to $35 \%$ of patients who are candidates to left VAD also have RV failure in the immediate postoperative period. With RV failure, there may be renal and hepatic dysfunction in the postoperative period, which is associated with high mortality. In the INTERMACS registration, among patients implanted for TD who also required RV support, mortality was $50 \%$ in three months. The assessment of RV function prior to implantation of the VAD is crucial and may prevent serious complications postoperatively.

The inability of the device to maintain the MCS is defined as malfunction. Many of these failures or complications can be life threatening. The device replacement may be necessary in many cases. In the REMATCH study, 11 (16\%) of 68 patients who received VAD died bacause of failure of the device ${ }^{60}$.

Surgical mortality remains a major concern of DT. The risk of death is higher for DT than for TB in different works ${ }^{61}$. The main causes of death were infection with sepsis, RV failure and multiple organ failure ${ }^{48}$. Analysis of the post-REMATCH study reveals that $75 \%$ of deaths during the first year of MCS occurred before hospital discharge ${ }^{62}$. The benefits of long-term support are evident as $78 \%$ survival rate at one year is observed in patients who were discharged from hospital ${ }^{62}$.

\section{Quality of life}

The rationale is that the therapy with VAD provides an improved quality of life of patients with terminal HF. Quality of life should be assessed in different ways, such as physical, psychological and social aspects, and general welfare. Studies have demonstrated improved quality of life of patients who received the devices compared to patients maintained on clinical therapy. However, patients with VAD have physical and social limitations that alter the general welfare. The potential for complications related to the devices requires patients to keep strict medical control, always close to the institutions responsible for the operation. So far, family members or caregivers of patients after VAD have not been studied with respect to potential psychological disorders, anxiety or depression while looking after these patients ${ }^{48}$. Although readmissions are common after VAD implantation and life threatening complications, patients have a good quality of life and are out of the hospital most of the time, without limitations in terms of HF symptoms ${ }^{40}$.

\section{Technology costs}

The TX is the most effective treatment for chronic HF. The costs are acceptable given the small number of procedures performed in the world. However, its epidemiological impact is still limited. On average in the world around 3000 TX are annually made ${ }^{63}$. The VAD has become more popular in Europe and the United States, due to good results and decreased complications with continuous-flow machines. However, the costs of this technology are still high. Digiorgi et $\mathrm{al}^{63}$ demonstrated that the length of hospitalization after implantation of VAD (36.8 days) is greater than that of patients who underwent TX (18.2 days $)^{63}$. Hospital costs for the implantation of VAD were US\$197,957 vs. US\$ 151,646 in patients undergoing TX. The costs are related to the period of hospitalization prior to VAD implantation (21.3 days) vs. (1.6 days) for the TX.

Cost-benefit issues considering the elderly and DT are unclear. In 2003, the U.S. Medicare expanded payment and included VAD as a DT. In 2008, Hernandez et $\mathrm{al}^{64}$ analyzed 64 patients who received treatment with VAD between 2000 and 2006 examining the outcome in the short and long term, including death, re-hospitalizations and in-hospital costs (335 
hospitals surveyed). Fifty-five point six percent of patients were readmitted within a period of six months after the operation. Concerning payment, in the first year Medicare paid out to hospital patients US\$178,714. These costs correspond to a liver transplant. The use of VAD therapy is expensive and high rate of hospital readmission is expected especially in the first six months after implantation. The NHLBI established in 2004 a goal of $50 \%$ survival rate at two years and a minimum length of stay as a prerequisite for a substantial increase in the implantation of the VAD as DT ${ }^{65}$. Hernandez et al ${ }^{64}$ observed survival of $65 \%$ in two years in patients who were discharged from hospital, which prompted the NHLBI to recommend a randomized study to compare early VAD and clinical treatment ${ }^{64}$. In 2011, a prospective randomized study (REVIVE-IT) begins to enroll VAD patients in functional class III vs. clinical treatment ${ }^{35,66}$.

During the clinical treatment of HF in the United States, Medicare pays US\$6,000 per admission even if the patient returns to hospital system within 30 days, a fact that occurs in $25 \%$ of cases $^{67}$. Seventy-five percent of Medicare spending in HF care is for hospitalized patients ${ }^{68}$.

\section{VAD in the world}

Of the 5.3 million patients with HF, about 150,000 are potential candidates for $\mathrm{MCS}^{69}$. Due to the severity of the clinical condition of these patients and the difficulty of their treatment, the literature offers limited documentation from randomized clinical trials. Maybe that is why, in 2009, less than 3,000 patients benefited from this treatment in the world despite falling costs and improved short-term outcomes ${ }^{70}$.

Therefore, to achieve the goal of treating more patients, in addition to the improvement of long-term results, the access of patients to VAD treatment is expected to expand. It is observed that, despite the impressive results shown by papers published, patients continue to be referred too late or they are not even referred $^{59}$.

In Europe, the movement of VAD use took a different path. A rapid and progressive increase in the use of MCS for the treatment of acute and chronic HF is observed, recently surpassing the number of TX. In the U.S., there is underutilization of VADs, however, there was a progressive increase in the number of implants ${ }^{35}$. Today, the percentage of patients who are transplanted with VAD is $40 \%$ nationally ${ }^{71}$. According to Miller et al., clinicians and cardiologists should be encouraged to refer patients with less advanced HF to VAD or TX ${ }^{35}$.

\section{VAD in Brazil}

The early use of MSC in Brazil occurred with the VAD-InCor, development in the early 1990s. This prototype is a ventricular assist device pneumatically actuated, membrane free, with smooth internal surface, bovine pericardial valves and paracorporeal installation. Its first clinical application occurred in 1993 in a patient who had cardiogenic shock refractory to drug therapy ${ }^{72}$. After four days of mechanical assistance, the patient underwent TX and was discharged in good condition ${ }^{73}$. This was a pioneering milestone in Brazil and Latin America. After the success of the first implant, the authors concluded that it opened the way for more frequent use of this technology, offering a new opportunity for patients awaiting TX, when the drug bridge is no longer effective.
In 2007, Moreira et al. implanted paracorporeal VAD in six patients with Chagas disease and demonstrated for the first time that this technology could be used safely in these patients, regardless of right ventricular dysfunction and arrhythmias ${ }^{74}$.

The first intracorporeal device (Heartmate XVE) was implanted in Brazil in 1999 in the city of Porto Alegre. There are several recent publications reporting Brazilian intracorporeal devices being investigated in national projects involving the creation of suspended circuit in magnetic fields producing efficient pumping and low possibility of mechanical failure ${ }^{75}$.

The number of device implants in Brazil has been sporadic and rare. Prototype development programs have not resulted in routine clinical implants yet. Despite the number of researches carried out in national institutions, no Brazilian VAD is offered to patients in advanced stages of $\mathrm{HF}^{76}$. Management of patients with chronic and irreversible heart failure is still done in most cases only with the aid of intravenous agents and TX as a last option ${ }^{22}$. In Brazil there is continuous availability of intracorporeal VAD. The Brazilian experience with MCS for clinical use is still limited to a few published cases ${ }^{77,78}$. The reasons for this fact are many, but certainly the explanation relies on the high cost of technology and lack of funding by the Brazilian public health system, which does not offers this treatment to the population. It should be noted that many Brazilian researchers have been working on developing national devices ${ }^{79}$ with the goal of providing the population with an artificial ventricle at a lower cost by providing easier access to this therapy. As a consequence of this work, new materials and new forms of blood propensity were developed and are rapidly evolving ${ }^{75,80}$.

Despite the clear advantage in the quality of life and prolongation of survival in patients with chronic HF, discussions about the economic impact that the use of the VAD would generate in the Brazilian health system should be made as soon as possible. The literature lack data to define precisely the costeffectiveness of treatment of patients with HF using VAD as TB or as $\mathrm{DT}^{70}$. Many patients with severe HF are not referred by general practitioners or cardiologists for the treatment or lack of information or hesitation related to the effectiveness of the VAD. With proper patient selection and increasing experience in the management of implant devices, the costs of patient care will diminish and allow Brazilian doctors to offer this innovative technology with proven effectiveness. This is a discussion that should occur with the Brazilian society and not just the medical community. Certainly, as reported by several studies in the medical literature, we have reason enough to incorporate this technology in Brazil in order to offer patients another treatment option, even if as TB.

\section{Potential Conflict of Interest}

No potential conflict of interest relevant to this article was reported.

\section{Sources of Funding}

There were no external funding sources for this study.

\section{Study Association}

This study is not associated with any post-graduation program. 


\section{References}

1. Thompson KA, Philip KJ, Barbagelata A, Schwarz ER. Review article: the new concept of interventional heart failure therapy--part 1: electrical therapy, treatment of CAD, fluid removal, and ventricular support. J Cardiovasc Pharmacol Ther. 2010;15(2):102-11.

2. Miller LW, Missov ED. Epidemiology of heart failure. Cardiol Clin. $2001 ; 19(4): 547-55$.

3. Park SJ, Tector A, Piccioni W, Raines E, Gelijns A, Moskowitz A, et al. Left ventricular assist devices as destination therapy: a new look at survival. J Thorac Cardiovasc Surg. 2005;129(1):9-17.

4. Rose EA, Gelijns AC, Moskowitz AJ, Heitjan DF, Stevenson LW, Dembitsky W, et al. Long-term use of a left ventricular assist device for end-stage heart failure. N Engl J Med. 2001;345(20):1435-43.

5. Hershberger RE, Nauman D, Walker TL, Dutton D, Burgess D. Care processes and clinical outcomes of continuous outpatient support with inotropes (COSI) in patients with refractory endstage heart failure. J Card Fail. 2003;9(3):180-7.

6. Strueber M, O'Driscoll G, Jansz P, Khaghani A, Levy WC, Wieselthaler GM; HeartWare Investigators. Multicenter evaluation of an intrapericardial left ventricular assist system. J Am Coll Cardiol. 2011;57(12):1375-82.

7. Owan TE, Hodge DO, Herges RM, Jacobsen SJ, Roger VL, Redfield MM. Trends in prevalence and outcome of heart failure with preserved ejection fraction. N Engl J Med. 2006;355(3):251-9.

8. Itchhaporia D. Heart failure readmission rates. Rev Cardiovasc Med. 2011;12(1):40-1.

9. Roger VL, Go AS, Lloyd-Jones DM, Adams RJ, BerryJD, Brown TM, et al. Heart disease and stroke statistics--2011 update: a report from the American Heart Association. Circulation. 2011;123(4):e18-e209.

10. Rogers JG, Butler J, Lansman SL, Gass A, Portner PM, Pasque MK, et al. Chronic mechanical circulatory support for inotrope-dependent heart failure patients who are not transplant candidates: results of the INTrEPID Trial. J Am Coll Cardiol. 2007;50(8):741-7.

11. Mancini D, Burkhoff D. Mechanical device-based methods of managing and treating heart failure. Circulation. 2005;112(3):438-48.

12. Abu-OmarY, Tsui SS. Mechanical circulatory support for AMI and cardiogenic shock. J Card Surg. 2010;25(4):434-41.

13. Jaski BE, Lingle RJ, Kim J, Branch KR, Goldsmith R, Johnson MR, et al. Comparison of functional capacity in patients with end-stage heart failure following implantation of a left ventricular assist device versus heart transplantation: results of the experience with left ventricular assist device with exercise trial. J Heart Lung Transplant. 1999;18(11):1031-40.

14. Fang JC. Rise of the machines--left ventricular assist devices as permanent therapy for advanced heart failure. N Engl J Med. 2009;361(23):2282-5.

15. Guan Y, Karkhanis T, Wang S, Rider A, Koenig SC, Slaughter MS, et al. Physiologic benefits of pulsatile perfusion during mechanical circulatory support for the treatment of acute and chronic heart failure in adults. Artif Organs. 2010;34(7):529-36.

16. Potapov EV, Krabatsch T, Ventura HO, Hetzer R. Advances in mechanical circulatory support: year in review. J Heart Lung Transplant. 2011;30(5):487-93.

17. Slaughter MS, Rogers JG, Milano CA, Russell SD, Conte JV, Feldman D, et al. Advanced heart failure treated with continuous-flow left ventricular assist device. N Engl J Med. 2009;361(23):2241-51.

18. Kozik DJ, Plunkett MD. Mechanical circulatory support. Organogenesis. $2011 ; 7(1): 50-63$.

19. Nose Y. Current status of the artificial heart program. Adv Biomed Eng Med Phys. 1970;3:3-4.

20. Goldstein DJ, Oz MC, Rose EA. Implantable left ventricular assist devices. N Engl J Med. 1998;339(21):1522-33.
21. Frazier OH, Rose EA, Macmanus Q, Burton NA, Lefrak EA, Poirier VL, et al. Multicenter clinical evaluation of the HeartMate 1000 IP left ventricular assist device. Ann Thorac Surg. 1992;53(6):1080-90.

22. Boilson BA, Raichlin E, Park SJ, Kushwaha SS. Device therapy and cardiac transplantation for end-stage heart failure. Curr Probl Cardiol. 2010;35(1):8-64.

23. Packer M, Fowler MB, Roecker EB, Coats AJ, Katus HA, Krum H, et al. Effect of carvedilol on the morbidity of patients with severe chronic heart failure: results of the carvedilol prospective randomized cumulative survival (COPERNICUS) study. Circulation. 2002;106(17):2194-9.

24. Kjekshus J, Swedberg K, Snapinn S. Effects of enalapril on long-term mortality in severe congestive heart failure. CONSENSUS Trial Group. Am J Cardiol. 1992;69(1):103-7.

25. Stevenson LW, Miller LW, Desvigne-Nickens P, Ascheim DD, Parides MK Renlund DG, et al. Left ventricular assist device as destination for patients undergoing intravenous inotropic therapy: a subset analysis from REMATCH (Randomized Evaluation of Mechanical Assistance in Treatment of Chronic Heart Failure). Circulation. 2004;110(8):975-81.

26. Topilsky Y, Maltais S, Oh JK, Atchison FW, Perrault LP, Carrier M, et al. Focused review on transthoracic echocardiographic assessment of patients with continuous axial left ventricular assist devices. Cardiol Res Pract. 2011:187434.

27. Letsou GV, Myers TJ, Gregoric ID, Delgado R, Shah N, Robertson K, et al. Continuous axial-flow left ventricular assist device (Jarvik 2000) maintains kidney and liver perfusion for up to 6 months. Ann Thorac Surg. 2003;76(4):1167-70.

28. Sayer G, Naka Y, Jorde UP. Ventricular assist device therapy. Cardiovasc Ther. $2009 ; 27(2): 140-50$.

29. Aggarwal S, Pagani FD. Bridge to transplantation: current outcomes. J Card Surg. 2010;25(4):455-61.

30. Hetzer R, Krabatsch T, Stepanenko A, Hennig E, Potapov E. Long-term biventricular support with the heartware implantable continuous flow pump. J Heart Lung Transplant. 2010;29(7):822-4.

31. Miller LW, Pagani FD, Russell SD, John R, Boyle AJ, Aaronson KD, et al. Use of a continuous-flow device in patients awaiting heart transplantation. $\mathrm{N}$ Engl J Med. 2007;357(9):885-96.

32. Pagani FD, Miller LW, Russell SD, Aaronson KD, John R, Boyle AJ, et al. Extended mechanical circulatory support with a continuous-flow rotary left ventricular assist device. J Am Coll Cardiol. 2009; 54(4):312-21.

33. Starling RC, Naka Y, Boyle AJ, Gonzalez-Stawinski G, John R, Jorde U, et al. Results of the post-U.S. Food and Drug Administration-approval study with a continuous flow left ventricular assist device as a bridge to heart transplantation: a prospective study using the INTERMACS (Interagency Registry for Mechanically Assisted Circulatory Support). J Am Coll Cardiol. 2011;57(19):1890-8.

34. Kirklin JK, Naftel DC, Kormos RL, Stevenson LW, Pagani FD, Miller MA, et al Second INTERMACS annual report: more than 1,000 primary left ventricular assist device implants. J Heart Lung Transplant. 2010;29(1):1-10.

35. Miller LW. Left ventricular assist devices are underutilized. Circulation. 2011;123(14):1552-8.

36. Kirklin JK, Naftel DC, Kormos RL, Stevenson LW, Pagani FD, Miller MA, et al. Third INTERMACS Annual Report: the evolution of destination therapy in the United States. J Heart Lung Transplant. 2011;30(2):115-23.

37. Kirklin JK, Naftel DC, Stevenson LW, Kormos RL, Pagani FD, Miller MA, et al. INTERMACS database for durable devices for circulatory support: first annual report. J Heart Lung Transplant. 2008;27(10):1065-72.

38. Lahpor J, Khaghani A, Hetzer R, Pavie A, Friedrich I, Sander K, et al. European results with a continuous-flow ventricular assist device for advanced heartfailure patients. Eur J Cardiothorac Surg. 2010;37(2):357-61. 


\section{Clinical Update}

39. Pruijsten RV, de Jonge N, Kirkels JH, Klöpping C, Doevendans PA, Oosterom A, et al. Left ventricular assist device: a functional comparison with heart transplantation. Neth HeartJ. 2008;16(2):41-6.

40. Allen JG, Weiss ES, Schaffer JM, Patel ND, Ullrich SL, Russell SD, et al. Quality of life and functional status in patients surviving 12 months after left ventricular assist device implantation. J Heart Lung Transplant. 2010;29(3):278-85 .

41. Marinho A. [A study on organ transplantation waiting lines in Brazil's Unified National Health System]. Cad Saude Publica. 2006;22(10):2229-39.

42. Dickstein K, Cohen-Solal A, Filippatos G, McMurray JJ, Ponikowski P, PooleSilson PA, et al. ESC guidelines for the diagnosis and treatment of acute and chronic heart failure 2008: the Task Force for the diagnosis and treatment of acute and chronic heart failure 2008 of the European Society of Cardiology. Developed in collaboration with the Heart Failure Association of the ESC (HFA) and endorsed by the European Society of Intensive Care Medicine (ESICM). Eur J Heart Fail. 2008;10(10):933-89.

43. Hunt SA, Abraham WT, Chin MH, Feldman AM, Francis GS, Ganiats TG, et al. 2009 Focused update incorporated into the ACC/AHA 2005 Guidelines for the Diagnosis and Management of Heart Failure in Adults A Report of the American College of Cardiology Foundation/American Heart Association Task Force on Practice Guidelines Developed in Collaboration With the International Society for Heart and Lung Transplantation. J Am Coll Cardiol. 2009;53(15):e1-e90.

44. Bocchi EA, Marcondes-Braga FG, Ayub-Ferreira SM, Rohde LE, Oliveira WA Almeida DR, et al.; Sociedade Brasileira de Cardiologia. III Diretriz brasileira de insuficiencia cardíaca cronica. Arq Bras Cardiol. 2009;93(1 supl. 1):1-71.

45. Lund LH, Matthews J, Aaronson K. Patient selection for left ventricular assist devices. Eur J Heart Fail. 2010;12(5):434-43.

46. Park SJ, Liao KK, Segurola R, Madhu KP, Miller LW. Management of aortic insufficiency in patients with left ventricular assist devices: a simple coaptation stitch method (Park's stitch). J Thorac Cardiovasc Surg. 2004;127(1):264-6.

47. Tsukui H, Abla A, Teuteberg JJ, McNamara DM, Mathier MA, Cardaret LM, et al. Cerebrovascular accidents in patients with a ventricular assist device. J Thorac Cardiovasc Surg. 2007;134(1):114-23

48. Rizzieri AG, Verheijde JL, Rady MY, McGregor JL. Ethical challenges with the left ventricular assist device as a destination therapy. Philos Ethics Humanit Med. 2008;3:20.

49. Meyer AL, Malehsa D, Bara C, Budde U, Slaughter MS, Haverich A, et al. Acquired von Willebrand syndrome in patients with an axial flow left ventricular assist device. Circ Heart Fail. 2010;3(6):675-81.

50. Gordon RJ, Quagliarello B, Lowy FD. Ventricular assist device-related infections. Lancet Infect Dis. 2006;6(7):426-37.

51. Awad H, Abd El Dayem M, Heard J, Dimitriva G, Yu L, Sun BC. Initial experience with off-pump left ventricular assist device implantation in single center: retrospective analysis. J Cardiothorac Surg. 2010;5:123.

52. McCarthy PM, Schmitt SK, Vargo RL, Gordon S, Keys TF, Hobbs RE. Implantable LVAD infections: implications for permanent use of the device. Ann Thorac Surg. 1996;61(1):359-65; discussion 372-3.

53. Genovese EA, Dew MA, Teuteberg JJ, Simon MA, Bhama JK, Bermudez CA, et al. Early adverse events as predictors of 1-year mortality during mechanical circulatory support. J Heart Lung Transplant. 2010;29(9):981-8.

54. Topkara VK, Kondareddy S, Malik F, Wang IW, Mann DL, Ewald GA, et al. Infectious complications in patients with left ventricular assist device: etiology and outcomes in the continuous-flow era. Ann Thorac Surg. 2010;90(4):1270-7.

55. Holman WL, Rayburn BK, McGiffin DC, Foley BA, Benza RL, Bourge RC. Infection in ventricular assist devices: prevention and treatment. Ann Thorac Surg. 2003;75(6 Suppl):S48-57.

56. Holman WL, Pamboukian SV, McGiffin DC, Tallaj JA, Cadeiras M, Kirklin JK. Device related infections: are we making progress? J Card Surg. 2010;25(4):478-83.
57. Chinn R, Dembitsky W, Eaton L, Chillcott S, Stahovich M, Rasmusson B, et al. Multicenter experience: prevention and management of left ventricular assist device infections. ASAIO J. 2005;51(4):461-70.

58. Pae WE, Connell JM, Adelowo A, Boehmer JP, Korfer R, El-Banayosy A, et al. Does total implantability reduce infection with the use of a left ventricular assist device? The LionHeart experience in Europe. J Heart Lung Transplant. $2007 ; 26(3): 219-29$.

59. Slaughter MS, Myers TJ. Transcutaneous energy transmission for mechanical circulatory support systems: history, current status, and future prospects. J Card Surg. 2010;25(4):484-9.

60. Dembitsky WP, Tector AJ, Park S, Moskowitz AJ, Gelijns AC, Ronan NS, et al. Left ventricular assist device performance with long-term circulatory support: lessons from the REMATCH trial. Ann Thorac Surg. 2004;78(6):2123-9; discussion 2129-30.

61. Lietz K. Destination therapy: patient selection and current outcomes. J Card Surg. 2010;25(4):462-71.

62. Lietz K, Long JW, Kfoury AG, Slaughter MS, Silver MA, Milano CA, et al. Outcomes of left ventricular assist device implantation as destination therapy in the post-REMATCH era: implications for patient selection. Circulation. 2007; 116(5):497-505.

63. Digiorgi PL, Reel MS, Thornton B, Burton E, Naka Y, Oz MC. Hearttransplant and left ventricular assist device costs. J Heart Lung Transplant. 2005;24(2):200-4.

64. Hernandez AF, Shea AM, Milano CA, Rogers JG, Hammill BG, O'Connor CM, et al. Long-term outcomes and costs of ventricular assist devices among Medicare beneficiaries. JAMA. 2008;300(20):2398-406

65. National Heart Lung and Blood Institute. NHLBI Working Group. Next generation ventricular assist devices for destination therapy. Stanford; 2005.

66. Baldwin JT, Mann DL. NHLBI's program for VAD therapy for moderately advanced heart failure: the REVIVE-IT pilot trial. J Card Fail. 2010;16(11):855-8.

67. Bogaev RC. Cost considerations in the treatment of heart failure. Tex Heart Inst J. 2010;37(5):557-8.

68. Lloyd-Jones D, Adams RJ, Brown TM, Carnethon M, Dai S, De Simone G, etal. Heart disease and stroke statistics--2010 update: a report from the American Heart Association. Circulation. 2010;121(7):e46-e215.

69. Ammar KA, Jacobsen SJ, Mahoney DW, Kors JA, Redfield MM, Burnett $J C \mathrm{Jr}$, et al. Prevalence and prognostic significance of heart failure stages: application of the American College of Cardiology/American Heart Association heart failure staging criteria in the community. Circulation. 2007;115(12):1563-70.

70. Hutchinson J, Scott DA, Clegg AJ, Loveman E, Royle P, Bryant J, et al. Costeffectiveness of left ventricular-assist devices in end-stage heart failure. Expert Rev Cardiovasc Ther. 2008;6(2):175-85

71. Lietz K, Miller LW. Will left-ventricular assist device therapy replace heart transplantation in the foreseeable future? Curr Opin Cardiol. 2005; 20(2):132-7.

72. Bocchi EA, Vieira ML, Fiorelli A, Hayashida S, Mayzato M, Leirner A, et al. [Hemodynamic and neurohormonal profile during assisted circulation with heterotopic artificial ventricle followed by heart transplantation]. Arq Bras Cardiol. 1994;62(1):23-7.

73. Oshiro MS, Hayashida SA, Maizato MJ, Marques EF, Stolf NA, Jatene AD, et al. Design, manufacturing, and testing of a paracorporeal pulsatile ventricular assist device: Sao Paulo Heart Institute VAD. Artif Organs. 1995;19(3):274-9.

74. Moreira LF, GalantierJ, Benicio A, Leirner AA, Cestari IA, Stolf NA. Left ventricular circulatory support as bridge to heart transplantation in Chagas' disease cardiomyopathy. Artif Organs. 2007;31(4):253-8.

75. da Silva I, Horikawa O, Cardoso JR, Camargo FA, Andrade AJ, Bock EG. Single axis controlled hybrid magnetic bearing for left ventricular assist device: hybrid core and closed magnetic circuit. Artif Organs. 2011; 35(5):448-53.

76. Moreira LF, Benicio A. Mechanical circulatory support: a great gap in Brazilian cardiac surgery. Rev Bras Cir Cardiovasc. 2010;25(4):X-XII. 
77. Colafranceschi AS, Monteiro AJ, Barbosa RM, Côrtes DC, Correa CM, Canale LS, et al. Use of mechanical circulatory support in cases of endstage acute heart failure. Arq Bras Cardiol. 2007;89(5):311-4, 343-5.

78. Galantier J, Moreira LF, Benicio A, Leirner AA, Cestari I, Bocchi EA, et al. Hemodynamic performance and inflammatory response during the use of VAD-InCor as a bridge to transplant. Arq Bras Cardiol. 2008;91(5):327-34 .
79. da Costa Teixeira PB, Goncalves PB, Cestari IA, Leirner AA, Pamplona D. Mechanical behavior and stability of the internal membrane of the InCor ventricular assist device. Artif Organs. 2001;25(11):912-21.

80. Horikawa O, de Andrade AJ, da Silva I, Bock EG. Magnetic suspension of the rotor of a ventricular assist device of mixed flow type. Artif Organs. 2008;32(4):334-41. 